\title{
Florística e estrutura da comunidade arbórea em fragmentos de floresta aluvial em São Sebastião da Bela Vista, Minas Gerais, Brasil
}

\author{
ANA CAROLINA DA SILVA ${ }^{1,5}$, EDUARDO VAN DEN BERG ${ }^{2}$, PEDRO HIGUCHI $^{1}$, \\ ARY TEIXEIRA DE OLIVEIRA-FILHO ${ }^{3}$, JOÃO JOSÉ GRANATE DE SÁ E MELO MARQUES ${ }^{4}$, \\ VIVETTE APPOLINÁRIO ${ }^{3}$, DANIEL SALGADO PIFANO ${ }^{3}$, \\ LEONARDO MASSAMITSU OGUSUKU ${ }^{3}$ e MATHEUS HENRIQUE NUNES ${ }^{3}$
}

(recebido: 17 de janeiro de 2008; aceito: 5 de março de 2009)

\begin{abstract}
Tree community floristic and structure of alluvial forest fragments in São Sebastião da Bela Vista, Minas Gerais, Brazil). Fragments of alluvial forest in the South of Minas Gerais, Brazil, were studied in order to assess the vegetation structure, tree diversity and the most influential environmental variables on vegetation variations. The environment and vegetation data $(\mathrm{dbh} \geq 5 \mathrm{~cm})$ were collected in $54,20 \times 10 \mathrm{~m}$, permanents plots allocated in a riverine forest and in five fragments of alluvial forests. In the plots, the survey totalled 2,064 tree individuals, distributed in 51 species. The canonical correspondence analysis detected a tree composition gradient in the first axis, related to $\mathrm{Mg}$, organic matter and $\mathrm{H}+\mathrm{Al}$ soil content, sand and clay percentage and soil water table level. The CCA second axis was associated with canopy coverage and soil silte percentage. Theses variables caused a plot group formation related to species distribution.
\end{abstract}

Key words - phytosociology, tree component, wetlands

RESUMO - (Florística e estrutura da comunidade arbórea em fragmentos de floresta aluvial em São Sebastião da Bela Vista, Minas Gerais, Brasil). O presente estudo avaliou a diversidade e estrutura da vegetação de fragmentos de floresta aluvial no Município de São Sebastião da Bela Vista, MG, e as principais variáveis ambientais que influenciam essa vegetação. Os estudos das variáveis ambientais (dados de amostras superficiais dos solos, nível freático no solo, cobertura do dossel e impactos ambientais) e da composição e estrutura da vegetação arbórea (DAP $\geq 5 \mathrm{~cm}$ ) foram conduzidos em 54 parcelas de $200 \mathrm{~m}^{2}$, alocadas em floresta ciliar com influência aluvial e em cinco fragmentos de floresta aluvial. Nas parcelas, foram registrados 2.064 indivíduos pertencentes a 51 espécies. A análise de correspondência canônica detectou gradiente de distribuição das espécies arbóreas no eixo 1, de acordo com os valores no solo de: profundidade do nível freático, porcentagem de areia e argila e teores de $\mathrm{Mg}$, matéria orgânica e $\mathrm{H}+\mathrm{Al}$. O eixo 2 esteve correlacionado com as variáveis cobertura do dossel e porcentagem de silte no solo. Estas variáveis ambientais ocasionaram a formação de grupos de parcelas, de acordo com a distribuição das espécies.

Palavras-chave - áreas inundáveis, componente arbóreo, fitossociologia

\section{Introdução}

Dentre os fatores que podem causar a fragmentação natural de hábitats estão incluídos os processos hidrogeológicos, que produzem áreas com inundação temporária ou permanente (MMA 2003), mescladas com áreas mais elevadas, com conseqüente menor saturação hídrica. Nas áreas mais baixas e saturadas, na maioria das vezes, há o impedimento de formação de vegetação

1. Universidade do Estado de Santa Catarina, Centro de Ciências Agroveterinárias, Departamento de Engenharia Florestal, Av. Luiz de Camões, 2090. B. Conta Dinheiro. 88520-000 Lages, SC, Brasil.

2. Universidade Federal de Lavras, Departamento de Biologia, 37200-000 Lavras, MG, Brasil.

3. Universidade Federal de Lavras, Departamento de Ciências Florestais, 37200-000 Lavras, MG, Brasil.

4. Universidade Federal de Lavras, Departamento de Ciências do Solo, 37200-000 Lavras, MG, Brasil.

5. Autor para correspondência: carol_sil4@yahoo.com.br arbórea, predominando uma vegetação herbácea adaptada, enquanto que nas elevações, há o desenvolvimento do estrato arbóreo, formando fragmentos florestais naturais que, durante a estação chuvosa, podem ser alagados. Além destas áreas, que normalmente estão em planícies associadas a cursos de água, existem as florestas ciliares sobre os diques, margeando o curso de água, que também podem estar sujeitas às inundações sazonais. Devido à intensidade e à frequiência das inundações, às mudanças graduais no curso da água e à dinâmica de remoção e deposição de sedimentos, a comunidade biótica das áreas sujeitas às inundações, denominada de floresta aluvial, está em constante instabilidade e reorganização, pois seu estabelecimento, crescimento e reprodução são influenciados pelos níveis da água (Salo \& Räsänem 1990).

Apesar de serem consideradas áreas de preservação permanente pela Lei número 4.771, de 15/09/1965, do 
Código Florestal (Milaré 1991), as matas ciliares, e entre elas as florestas aluviais, estão entre as mais ameaçadas, pois são sistemas complexos (Rodrigues \& Nave 2000) e frágeis ao impacto antrópico (van den Berg \& OliveiraFilho 2000). Muitas destas florestas, essenciais para a manutenção dos recursos hídricos, a proteção de cursos de água, além de servirem como corredores ecológicos e hábitat para a flora e a fauna (Barrella et al. 2000, Lino \& Dias 2003), estão também fragmentadas, devido às ações antrópicas.

Em Minas Gerais, poucos estudos fitossociológicos têm sido realizados em florestas aluviais, dentre os quais se destacam os realizados na bacia do Rio Grande (Botrel et al. 2002, Pereira et al. 2006, Vilela et al. 2000, van den Berg et al. 2006), bacia do Rio Doce (Meira Neto et al. 1997, Meira Neto et al. 2003) e na bacia do Rio Paranaíba (Schiavini 1992). Na sub-bacia do Rio Sapucaí, pertencente à bacia do Rio Grande, não foi encontrado nenhum estudo. Considerando a importância das áreas aluviais, assim como a escassez de estudos nestas florestas, os objetivos deste trabalho foram: i) conhecer a diversidade e a estrutura da vegetação de fragmentos de floresta aluvial no Médio Sapucaí, no Sul do Estado de Minas Gerais e ii) identificar as principais variáveis ambientais que influenciam essa vegetação. As hipóteses foram: i) áreas aluviais possuem baixa diversidade e elevada dominância ecológica; ii) o componente arbóreo dos fragmentos estudados apresenta variações florísticas e estruturais que refletem a heterogeneidade ambiental definida pelas variações na profundidade de nível freático e características físico-químicas no solo, cobertura do dossel e na intensidade dos impactos ambientais.

\section{Material e métodos}

Descrição das áreas de estudo e desenho amostral - Foram estudados um fragmento de mata ciliar e cinco fragmentos florestais na planície aluvial após o dique da mata ciliar (figura 1) localizados no Município de São Sebastião da Bela Vista, Minas Gerais, nas coordenadas geográficas limites de latitude $22^{\circ} 05^{\prime} 57^{\prime \prime} \mathrm{S}$ a $22^{\circ} 07^{\prime} 22,5^{\prime \prime} \mathrm{S}$ e longitude $45^{\circ} 48^{\prime} 05^{\prime}$ 'W a $45^{\circ} 48$ '53, 5" W, a 809 m de altitude. A região está localizada na bacia hidrográfica do Rio Sapucaí, que integra a bacia do Rio Grande, com relevo predominante entre o plano e o suave ondulado, com as formas planas sujeitas às inundações periódicas. Junto ao Rio Sapucaí, além da mata ciliar, existem vários fragmentos florestais naturais e antropizados, que estão localizados em matriz de vegetação herbácea associada a solos com condições de saturação hídrica inviáveis ao estabelecimento da vegetação arbórea. Nas partes mais elevadas do relevo, o grau de saturação hídrica diminui e há o estabelecimento do componente arbóreo, formando, assim, fragmentos em meio a áreas mais saturadas. Segundo a classificação de Köppen, o clima predominante na região é mesotérmico úmido, com dois a três meses secos ao ano, enquadrado no tipo $\mathrm{Cwb}$ (temperatura média do mês mais frio inferior a $18{ }^{\circ} \mathrm{C}$ e do mês mais quente não ultrapassa $22^{\circ} \mathrm{C}$ ) (Brasil 1992). A região Sul mineira enquadra-se em zona de influência dos domínios vegetacionais do Cerrado e da Floresta Atlântica (Rizzini 1997) e as formações florestais são classificadas como Florestas Estacionais Semideciduais Aluviais (IBGE 1992).

Os estudos das variáveis ambientais e da composição e estrutura da vegetação arbórea foram conduzidos em 54 parcelas de $200 \mathrm{~m}^{2}(10 \times 20 \mathrm{~m})$, totalizando 1,08 ha de área amostrada. Foram alocadas 24 parcelas na mata ciliar e seis em cada um dos cinco fragmentos aluviais estudados. As parcelas foram distribuídas nas áreas, de forma a amostrar adequadamente as suas variações ambientais, tendo, em cada fragmento, sido alocadas três parcelas nas bordas e três no interior do fragmento, com exceção do fragmento 5, onde todas as parcelas foram alocadas na borda ou próxima a esta, devido ao seu tamanho reduzido e formato alongado. Foi considerada como borda a área localizada nos primeiros $15 \mathrm{~m}$ para o interior da floresta, devido às pequenas dimensões dos fragmentos e pequena largura da mata ciliar. Embora alguns autores considerarem que o efeito borda possa ocorrer em distâncias maiores (e.g. Murcia 1995), é nos primeiros metros que os efeitos são mais intensos.

$\mathrm{Na}$ mata ciliar, foram alocadas nove parcelas na borda junto ao rio, nove parcelas na borda junto à matriz de campo circundante, e seis parcelas no interior da mata ciliar. $\mathrm{O}$ fato de a mata ciliar ser muito estreita em alguns trechos explica a menor quantidade de parcelas no seu interior. A borda ao lado do rio está mais propensa ao alagamento sazonal e possui o terreno mais baixo, que vai se tornando mais alto, à medida que se aproxima do interior da mata, formando um dique. Já os fragmentos florestais estão localizados na planície aluvial (figura 1).

Variáveis ambientais - Os solos de cada parcela foram classificados, no campo, de acordo com o Sistema Brasileiro de Classificação dos Solos (Embrapa 1999) até o quarto grupo categórico e suas propriedades físico-químicas obtidas por meio de amostras compostas em cada parcela, oriundas de três coletas realizadas no perfil de 0 a $20 \mathrm{~cm}$. As análises foram realizadas nos Laboratórios de Fertilidade e de Física de Solos da Universidade Federal de Lavras (UFLA), seguindo o protocolo da Embrapa (1997). Foram quantificados pH, fósforo $(\mathrm{P})$, potássio $(\mathrm{K})$, cálcio $(\mathrm{Ca})$, magnésio $(\mathrm{Mg})$, matéria orgânica (MO) e teores de areia, silte e argila nos solos, e também calculado o índice $\mathrm{H}+\mathrm{Al}$. A altura do nível freático no solo de cada parcela foi mensurada uma vez a cada dois meses, durante um ano, por meio da instalação de poços de observação de um metro de profundidade (Barddal et al. 2004, Ivanauskas 2002).

Para verificar a cobertura do dossel, foram feitas observações da luminosidade no centro de cada parcela e 
atribuídas notas de zero a cinco, em que zero correspondeu à menor abertura observada e cinco à maior abertura observada. A avaliação dos impactos ambientais foi feita por meio da observação de presença de trilhas, de impactos

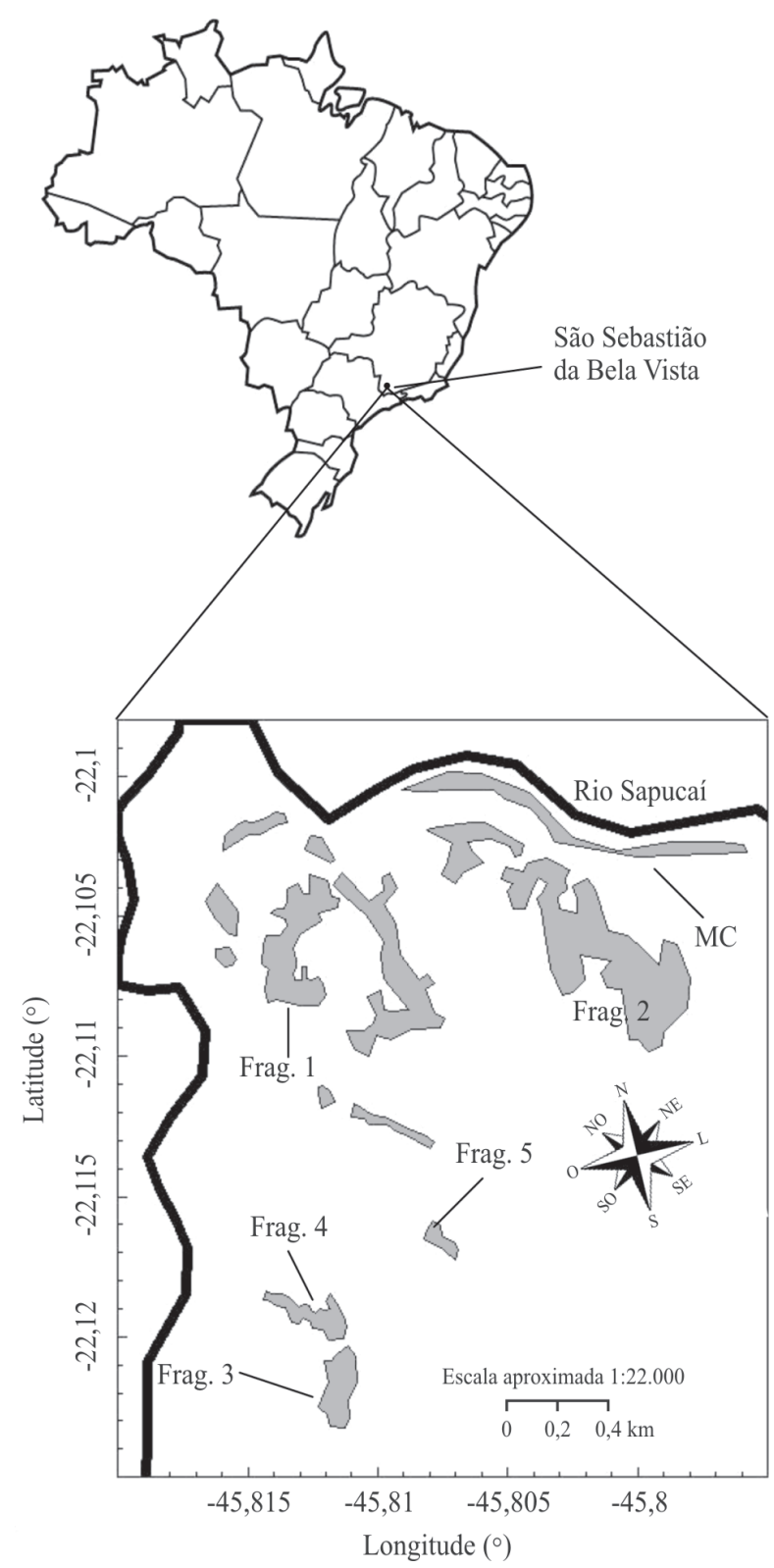

Figura 1. Mata ciliar (MC) e fragmentos florestais estudados no Município de São Sebastião da Bela Vista, Minas Gerais, Brasil. Em preto, a representação do Rio Sapucaí, os fragmentos florestais presentes na área estão em cinza e, em branco, a matriz não florestal.

Figure 1. Riparian forest (MC) and alluvial forest fragments studied in the municipality of São Sebastião da Bela Vista, Minas Gerais, Brazil. In black, is the representation of Rio Sapucaí, the forest fragments in the area are represented in gray and, in white, the non-forest matrix. causados pelo gado e do corte seletivo de árvores dentro das parcelas. Foram atribuídas notas de zero a cinco, sendo zero para a ausência de impacto observável.

Composição e estrutura da vegetação arbórea - Todos os indivíduos arbóreos vivos que apresentaram diâmetro medido a 1,30 $\mathrm{m}$ de altura (DAP) igual ou superior a $5 \mathrm{~cm}$ foram identificados e mensurados (DAP e altura total). Indivíduos com caules múltiplos foram medidos quando a soma das áreas basais das secções dos caules correspondia a uma área basal igual ou maior que a de um caule único com $5 \mathrm{~cm}$ de DAP. As identificações foram realizadas por meio de consultas a especialistas, à literatura e herbários. Os espécimes coletados foram depositados no Herbário ESAL (UFLA). As espécies foram classificadas nas famílias reconhecidas pelo sistema APG II (2003) e as grafias dos nomes dos autores foram uniformizadas, seguindo a padronização proposta por Brummitt \& Powell (1992).

Análise dos dados - Foram realizadas análises usando o teste de Kruskal-Wallis, no programa Statistica (StatSoft 2001), para a comparação entre as classes de solo encontradas em termos das médias das variáveis químicas, texturais e de nível freático no solo.

A diversidade foi avaliada pelo índice de ShannonWiener (H'), equabilidade de Pielou (J') (Brower \& Zar 1984) e o estimador de riqueza Jackknife de primeira e segunda ordem (Heltsche \& Forrester 1983), calculados pelo programa R (R Development Core Team 2005).

A estrutura do componente arbóreo foi descrita a partir do cálculo, para cada espécie, dos parâmetros quantitativos (Mueller-Dombois \& Ellenberg 1974): densidade absoluta e relativa, freqüência absoluta e relativa, dominância absoluta e relativa e valor de importância (VI). A distribuição diamétrica foi representada para: i) as três espécies com maior VI, ii) a comunidade da área total, e iii) a comunidade de cada fragmento e da mata ciliar. As classes de distribuição de diâmetro foram definidas de forma a ajustarem-se aos números de indivíduos encontrados e à amplitude da variação do diâmetro na área, conforme a seguir: Classe 1, de 5 a $8,9 \mathrm{~cm}$; Classe 2, de 9 a 16,9 cm; Classe 3, de 17 a 32,9 cm; Classe 4, de 33 a 64,9 cm e Classe 5, acima de $65 \mathrm{~cm}$. Como sugerido por Oliveira-Filho et al. (2001), foram empregados intervalos de classe com amplitudes exponencial crescentes para compensar o decréscimo da densidade nas classes de tamanho maiores, típico da distribuição J-invertido. De acordo com os mesmos autores, estes intervalos permitem melhor representação das classes diamétricas maiores e de baixa densidade, o que é desejável em comparações gráficas.

Para o estudo das interações entre espécies $(\geq 5$ indivíduos) e variáveis ambientais, foi empregada a Análise de Correspondência Canônica (CCA) (ter Braak 1987), junto com o teste de permutação de Monte Carlo, para a verificação das significâncias, no programa PC-ORD versão 4.14 (McCune \& Mefford 1999). Após análises preliminares, foram eliminadas as variáveis com correlações fracas com os dois primeiros eixos de ordenação $(r<0,5)$. 


\section{Resultados e discussão}

Variáveis edáficas - Foram identificadas quatro classes de solos: Neossolos Flúvicos Tb distróficos câmbicos (RUbd), situados na mata ciliar (parcelas 1 a 24); Cambissolos Húmicos Tb distróficos gleicos $(\mathrm{CHd})$, situados no fragmento 2 (parcelas 31 a 36) e em duas parcelas do fragmento 1 ( 28 e 30), ambientes mais secos entre os fragmentos; Gleissolos Melânicos distróficos hísticos (GMdh), situados nos fragmentos 3 e 4 (parcelas 37 a 48), na maioria das parcelas do fragmento 1 (25 a 27 e 29) e nas parcelas 49 e 51 a 53 do fragmento 5 , ambientes com nível freático próximo à superfície do solo a alagados no período de maior pluviosidade, e Gleissolos Melânicos distróficos típicos (GMdt), localizados nas parcelas 50 e 54 do fragmento 5, parcelas menos saturadas deste fragmento. No fragmento 1, houve predominância do solo GMdh, que é um solo mais saturado. Porém, duas parcelas de interior (28 e 30) obtiveram o solo CHd, com menor saturação hídrica. Isso ocorreu porque, nesse fragmento, as parcelas próximas da borda estão em um nível do terreno mais baixo, com nível freático próximo à superfície do solo, enquanto que as parcelas de interior apresentaram menor influência da água.

$\mathrm{P}, \mathrm{Ca}, \mathrm{Mg}, \mathrm{H}+\mathrm{Al}, \mathrm{pH}$ e $\mathrm{MO}$ foram significativamente diferentes entre os tipos de solos (Neossolos, Cambissolos e Gleissolos), assim como as variáveis texturais porcentagem de areia, silte e argila e o nível freático no solo (tabela 1). Os Neossolos, tipo de solo encontrado na área de mata ciliar, são solos mais bem drenados que os solos dos fragmentos, apresentando maior porcentagem de areia e menor de argila no perfil superficial. Neste solo, não foi registrada água a $1 \mathrm{~m}$ de profundidade, em todos os meses, nos poços de observação, resultando em menor acúmulo de matéria orgânica, ao contrário dos outros tipos de solos. Os Gleissolos, que foram os solos mais saturados, com nível freático mais próximo à superfície, obtiveram maior acúmulo de matéria orgânica, resultando em grande quantidade de $\mathrm{P}$ e $\mathrm{H}+$ Al disponível. Em um gradiente de saturação hídrica, os Cambissolos foram solos intermediários entre os Neossolos e Gleissolos, obtendo também, algumas vezes, valores intermediários das outras variáveis mensuradas (tabela 1).

Florística, estrutura e diversidade do componente arbóreo - Foram identificadas 82 espécies, pertencentes a 62 gêneros e a 34 famílias botânicas nas áreas aluviais estudadas (tabela 2). As famílias com maior número de espécies foram Myrtaceae, com 17 espécies, seguida por Fabaceae com 12 espécies e Lauraceae, com sete espécies, que, juntas, respondem por 43,9\% da riqueza. Em diversos

Tabela 1. Variáveis químicas e texturais do perfil superficial dos solos $(0-20 \mathrm{~cm})$ e nível freático observados em 54 parcelas amostradas na mata ciliar e em cinco fragmentos de floresta aluvial em São Sebastião da Bela Vista, MG. Os valores são médias das $n$ amostras de cada um dos três tipos de solos. Teste de Kruskal-Wallis entre os tipos de solos. Valores de $P$ indicam sua significância.

Table 1. Chemical and textural variables of surface soil profile $(0-20 \mathrm{~cm})$ and water table level observed in 54 plots sampled in riparian and five alluvial forest fragments in São Sebastião da Bela Vista, MG. The values represent the means of $n$ samples from each of three soils types. Kruskal-Wallis test between the soils types. $P$-values indicate its significance.

\begin{tabular}{lcccc}
\hline Variáveis & $\begin{array}{c}\text { Neossolos } \\
(n=24)\end{array}$ & $\begin{array}{c}\text { Cambissolos } \\
(n=8)\end{array}$ & $\begin{array}{c}\text { Gleissolos } \\
(n=22)\end{array}$ & $P$ \\
\hline $\mathrm{pH} \mathrm{em} \mathrm{H} \mathrm{H}_{2} \mathrm{O}$ & 4,58 & 4,61 & 4,65 & 0,0226 \\
$\mathrm{P}-\mathrm{Mehlich}\left(\mathrm{mg} \mathrm{dm}^{-3}\right)$ & 9,01 & 6,34 & 18,62 & $<10^{-4}$ \\
$\mathrm{~K}^{+}\left(\mathrm{mg} \mathrm{dm}^{-3}\right)$ & 50,58 & 41,88 & 49,41 & 0,1436 \\
$\mathrm{Ca}^{++}\left(\mathrm{cmolc} \mathrm{dm}^{-3}\right)$ & 1,23 & 0,79 & 0,87 & 0,0019 \\
$\mathrm{Mg}^{++}\left(\mathrm{cmolc} \mathrm{dm}^{-3}\right)$ & 0,88 & 0,29 & 0,38 & 0,0002 \\
$\mathrm{H}^{++}+\mathrm{Al}^{+++}\left(\mathrm{cmolc} \mathrm{dm}^{-3}\right)$ & 9,06 & 12,16 & 14,62 & $<10^{-4}$ \\
${\mathrm{Matéria} \mathrm{orgânica}\left(\mathrm{dag} \mathrm{kg}^{-1}\right)}_{\text {Areia }(\%)}^{4,03}$ & 7,48 & 9,9 & $<10^{-4}$ \\
Silte $(\%)$ & 28,46 & 9,25 & 6,7 & $<10^{-4}$ \\
Argila $(\%)$ & 38,13 & 20,25 & 28,59 & $<10^{-4}$ \\
Prof. média do nível freático $(\mathrm{cm})$ & 33,42 & 70,50 & 64,68 & $<10^{-4}$ \\
Prof. mínima do nível freático $(\mathrm{cm})$ & $<-100,00$ & $-90,15$ & $-42,82$ & $<10^{-4}$ \\
\hline
\end{tabular}


estudos, como Loures (2006), em mata paludosa e Araujo et al. (2004), em floresta aluvial, foi encontrado Myrtaceae como a família mais abundante, indicando ser uma família com espécies adaptadas à saturação hídrica. Myrtaceae é também uma das maiores famílias da flora brasileira (Souza \& Lorenzi 2005), sendo encontrada em diferentes ecossistemas. Os gêneros com maior número de espécies foram Myrcia (6), Eugenia (5), Machaerium (3), Nectandra (3) e Ocotea (3) que, juntos, representam $24,4 \%$ do total das espécies.

Nas 54 parcelas, foram amostrados 2.064 indivíduos, pertencentes a 51 espécies, 40 gêneros e 23

Tabela 2. Espécies arbustivo-arbóreas encontradas na mata ciliar e nos fragmentos de floresta aluvial localizados no Município de São Sebastião da Bela Vista, MG, com seus respectivos números de registro no Herbário ESAL. (P = espécies amostradas nas parcelas; $\mathrm{F}=$ espécies registradas na florística; * = sem coleta.)

Table 2. Tree species found in the riparian and alluvial fragments forest located in the municipality of São Sebastião da Bela Vista, MG, Brazil, with their registry number in ESAL Herbarium. $(\mathrm{P}=$ species sampled in plots; $\mathrm{F}=$ species registered in the floristic; $*=$ no collection.)

\begin{tabular}{|c|c|c|}
\hline Famílias/Espécies & Ocorrência & Número de registro \\
\hline $\begin{array}{l}\text { ANACARDIACEAE } \\
\text { Tapirira guianensis Aubl. }\end{array}$ & $\mathrm{F}$ & 20.483 \\
\hline $\begin{array}{l}\text { ANNONACEAE } \\
\text { Duguetia lanceolata A. St.-Hil. } \\
\text { Rollinia emarginata } \text { Schltdl. }\end{array}$ & $\begin{array}{l}\mathrm{P} \\
\mathrm{P}\end{array}$ & $\begin{array}{l}20.484 \\
20.485\end{array}$ \\
\hline $\begin{array}{l}\text { APOCYNACEAE } \\
\text { Aspidosperma cylindrocarpon Müll. Arg. }\end{array}$ & $\mathrm{F}$ & 20.486 \\
\hline $\begin{array}{l}\text { ARECACEAE } \\
\text { Syagrus romanzoffiana (Cham.) Glassman }\end{array}$ & $\mathrm{P}$ & 20.487 \\
\hline $\begin{array}{l}\text { BORAGINACEAE } \\
\text { Cordia magnoliifolia } \text { Cham. }\end{array}$ & $\mathrm{F}$ & 20.489 \\
\hline $\begin{array}{l}\text { CANELLACEAE } \\
\text { Capsicodendron dinisii (Schwacke) Occhioni }\end{array}$ & $\mathrm{P}$ & 20.500 \\
\hline $\begin{array}{l}\text { CANNABACEAE } \\
\text { Trema micrantha }(\mathrm{L} .) \text { Blume }\end{array}$ & $\mathrm{F}$ & 20.490 \\
\hline $\begin{array}{l}\text { CELASTRACEAE } \\
\text { Maytenus salicifolia } \text { Reissek }\end{array}$ & $\mathrm{P}$ & 20492 \\
\hline $\begin{array}{l}\text { EUPHORBIACEAE } \\
\text { Alchornea triplinervia (Spreng.) Müll. Arg. } \\
\text { Croton urucurana Baill. } \\
\text { Gymnanthes concolor (Spreng.) Müll. Arg. } \\
\text { Sebastiania commersoniana (Baill.) L. B. Sm. \& Downs }\end{array}$ & $\begin{array}{l}\mathrm{P} \\
\mathrm{P} \\
\mathrm{F} \\
\mathrm{P}\end{array}$ & $\begin{array}{l}20.497 \\
20.498 \\
20.495 \\
20.504\end{array}$ \\
\hline $\begin{array}{l}\text { FABACEAE (CAESALPINIOIDEAE) } \\
\text { Copaifera langsdorffii Desf. } \\
\text { Hymenaea courbaril L. }\end{array}$ & $\begin{array}{l}\mathrm{P} \\
\mathrm{F}\end{array}$ & $\begin{array}{l}20.520 \\
20.522\end{array}$ \\
\hline $\begin{array}{l}\text { FABACEAE (FABOIDEAE) } \\
\text { Andira fraxinifolia } \text { Benth. } \\
\text { Andira vermifuga Mart. ex Benth. } \\
\text { Erythrina falcata } \text { Benth. } \\
\text { Lonchocarpus cultratus (Vell.) Az. Tozzi \& H. C. Lima } \\
\text { Machaerium hirtum (Vell.) Stellfeld } \\
\text { Machaerium nyctitans (Vell.) Benth. } \\
\text { Machaerium villosum Vogel } \\
\text { Platycyamus regnellii Benth. }\end{array}$ & $\begin{array}{l}\mathrm{P} \\
\mathrm{P} \\
\mathrm{P} \\
\mathrm{F} \\
\mathrm{F} \\
\mathrm{F} \\
\mathrm{F} \\
\mathrm{F}\end{array}$ & $\begin{array}{c}20.523 \\
20.524 \\
20.526 \\
20.528 \\
20.529 \\
20.531 \\
* \\
20.532\end{array}$ \\
\hline
\end{tabular}


continuação

\begin{tabular}{|c|c|c|}
\hline Famílias/Espécies & Ocorrência & Número de registro \\
\hline \multicolumn{3}{|l|}{ FABACEAE (MIMOSOIDEAE) } \\
\hline Acacia polyphylla DC. & $\mathrm{F}$ & 20.533 \\
\hline Inga vera Willd. & $\mathrm{P}$ & 20.534 \\
\hline \multicolumn{3}{|l|}{ LACISTEMATACEAE } \\
\hline Lacistema hasslerianum Chodat & $\mathrm{P}$ & 20.541 \\
\hline \multicolumn{3}{|l|}{ LAMIACEAE } \\
\hline Vitex megapotamica (Spreng.) Moldenke & $\mathrm{P}$ & 20.542 \\
\hline \multicolumn{3}{|l|}{ LAURACEAE } \\
\hline Cryptocarya saligna $\mathrm{Mez}$ & $\mathrm{P}$ & 20.505 \\
\hline Nectandra megapotamica (Spreng.) Mez & $\mathrm{P}$ & 20.506 \\
\hline Nectandra nitidula Nees \& Mart. & $\mathrm{P}$ & 20.508 \\
\hline Nectandra oppositifolia Nees \& Mart. & $\mathrm{F}$ & 20.513 \\
\hline Ocotea elegans $\mathrm{Mez}$ & $\mathrm{F}$ & 20.514 \\
\hline Ocotea indecora (Schott) Mez & $\mathrm{P}$ & 20.515 \\
\hline Ocotea velutina (Nees) Rohwer & $\mathrm{F}$ & 20.517 \\
\hline \multicolumn{3}{|l|}{ LECYTHIDACEAE } \\
\hline Cariniana estrellensis (Raddi) Kuntze & $\mathrm{F}$ & 20.518 \\
\hline \multicolumn{3}{|l|}{ LOGANIACEAE } \\
\hline Strychnos brasiliensis (Spreng.) Mart. & $\mathrm{F}$ & 20.519 \\
\hline \multicolumn{3}{|l|}{ MALVACEAE } \\
\hline Ceiba speciosa (A. St.-Hil.) Ravenna & $\mathrm{F}$ & * \\
\hline Luehea candicans Mart. & $\mathrm{F}$ & 20.543 \\
\hline \multicolumn{3}{|l|}{ MELASTOMATACEAE } \\
\hline Leandra gardneriana Cogn. & $\mathrm{F}$ & 20.544 \\
\hline Miconia paulensis Naud. & $\mathrm{P}$ & 20.548 \\
\hline \multicolumn{3}{|l|}{ MELIACEAE } \\
\hline Guarea macrophylla Vahl & $\mathrm{P}$ & 20.550 \\
\hline Trichilia catigua A. Juss. & $\mathrm{F}$ & 20.555 \\
\hline Trichilia pallida Sw. & $\mathrm{P}$ & 20.556 \\
\hline \multicolumn{3}{|l|}{ MONIMIACEAE } \\
\hline Mollinedia widgrenii A. DC. & $\mathrm{F}$ & 20.559 \\
\hline \multicolumn{3}{|l|}{ MORACEAE } \\
\hline Ficus luschnathiana (Miq.) Miq. & $\mathrm{P}$ & 20.560 \\
\hline Maclura tinctoria (L.) D. Don ex Steud. & $\mathrm{F}$ & 20.561 \\
\hline Sorocea bonplandii (Baill.) W.C. Burger, Lanj. \& Wess. Boer & $\mathrm{P}$ & 20.562 \\
\hline \multicolumn{3}{|l|}{ MYRSINACEAE } \\
\hline Myrsine gardneriana A. DC. & $\mathrm{P}$ & 20.563 \\
\hline \multicolumn{3}{|l|}{ MYRTACEAE } \\
\hline Calycorectes psidiiflorus (O. Berg) Sobral & $\mathrm{P}$ & 20.566 \\
\hline Calyptranthes widgreniana $\mathrm{O}$. Berg & $\mathrm{P}$ & 20.568 \\
\hline Campomanesia guaviroba (DC.) Kiaersk. & $\mathrm{P}$ & 20.570 \\
\hline Eugenia blastantha (O.Berg) D. Legrand & $\mathrm{P}$ & 20.571 \\
\hline Eugenia dodonaeaefolia Cambess. & $\mathrm{P}$ & 20.574 \\
\hline Eugenia florida DC. & $\mathrm{P}$ & 20.575 \\
\hline Eugenia cf myrciariifolia Soares-Silva \& Sobral & $\mathrm{P}$ & 20.600 \\
\hline Eugenia sp. & $\mathrm{P}$ & 20.583 \\
\hline Myrcia laruotteana Cambess. & $\mathrm{P}$ & 20.585 \\
\hline Myrcia multiflora (Lam.) DC. & $\mathrm{P}$ & 20.586 \\
\hline Myrcia oblongata DC. & $\mathrm{P}$ & 20.590 \\
\hline
\end{tabular}


continuação

\begin{tabular}{|c|c|c|}
\hline Famílias/Espécies & Ocorrência & Número de registro \\
\hline Myrcia pulchra (O. Berg) Kiaersk. & $\mathrm{P}$ & 20.596 \\
\hline Myrcia tomentosa (Aubl.) DC. & $\mathrm{F}$ & 20.597 \\
\hline Myrcia undulata $\mathrm{O}$. Berg & $\mathrm{P}$ & 20.598 \\
\hline Myrciaria tenella (DC.) O. Berg & $\mathrm{P}$ & 20.603 \\
\hline Plinia cauliflora (DC.) Kausel & $\mathrm{P}$ & 20.606 \\
\hline Psidium guajava $\mathrm{L}$. & $\mathrm{F}$ & 20.607 \\
\hline \multicolumn{3}{|l|}{ PICRAMNIACEAE } \\
\hline Picramnia sellowii Planch. & $\mathrm{P}$ & 20.608 \\
\hline \multicolumn{3}{|l|}{ PIPERACEAE } \\
\hline Piper gaudichaudianum Kunth & $\mathrm{F}$ & 20.611 \\
\hline \multicolumn{3}{|l|}{ RUBIACEAE } \\
\hline Faramea multiflora A. Rich. ex DC. & $\mathrm{F}$ & 20.612 \\
\hline Guettarda viburnoides Cham. \& Schltdl. & $\mathrm{P}$ & 20.613 \\
\hline \multicolumn{3}{|l|}{ SALICACEAE } \\
\hline Casearia sylvestris $\mathrm{Sw}$. & $\mathrm{P}$ & 20.614 \\
\hline Xylosma prockia (Turcz.) Turcz. & $\mathrm{P}$ & 20.615 \\
\hline Xylosma venosa N.E. Br. & $\mathrm{P}$ & 20.618 \\
\hline \multicolumn{3}{|l|}{ SAPINDACEAE } \\
\hline Cupania ludowigii Somner \& Ferrucci & $\mathrm{P}$ & 20.620 \\
\hline Cupania vernalis Cambess. & $\mathrm{F}$ & 20.621 \\
\hline \multicolumn{3}{|l|}{ SAPOTACEAE } \\
\hline Pouteria gardneriana (A. DC.) Radlk. & $\mathrm{P}$ & 20.623 \\
\hline \multicolumn{3}{|l|}{ SOLANACEAE } \\
\hline Solanum pseudoquina A. St.-Hil. & $\mathrm{F}$ & 20.624 \\
\hline \multicolumn{3}{|l|}{ SYMPLOCACEAE } \\
\hline Symplocos tetrandra Mart. & $\mathrm{P}$ & 20.626 \\
\hline Symplocos uniflora (Pohl) Benth. & $\mathrm{P}$ & 20.628 \\
\hline \multicolumn{3}{|l|}{ THYMELAEACEAE } \\
\hline Daphnopsis fasciculata (Meisn.) Nevling & $\mathrm{P}$ & 20.632 \\
\hline \multicolumn{3}{|l|}{ URTICACEAE } \\
\hline Cecropia pachystachya Trécul & $\mathrm{P}$ & 20.633 \\
\hline \multicolumn{3}{|l|}{ VERBENACEAE } \\
\hline Citharexylum myrianthum Cham. & $\mathrm{F}$ & 20.634 \\
\hline \multicolumn{3}{|l|}{ VOCHYSIACEAE } \\
\hline Vochysia magnifica Warm. & $\mathrm{F}$ & 20.635 \\
\hline
\end{tabular}

famílias botânicas (tabela 3), ou seja, 31 espécies $(37,80 \%)$ foram registradas fora das parcelas, inclusive em locais relativamente mais secos, como no dique de origem antrópica que atravessa o fragmento 4. Porém, as 51 espécies encontradas dentro das parcelas representam $82,4 \%$ a $85,2 \%$ da riqueza esperada pelos estimadores Jackknife de primeira e segunda ordem, que tiveram valores de 59,9 e 61,9 espécies, respectivamente. No levantamento florístico, o número de espécies foi de 82 , superando o número de espécies esperado pelos estimadores Jackknife.
Sebastiania commersoniana $(\mathrm{VI}=28,4 \%)$, com 791,67 ind ha ${ }^{-1}$ presentes em 52 das 54 parcelas, Inga vera $(\mathrm{VI}=13,6 \%)$ e Guarea macrophylla $(\mathrm{VI}=11,9 \%)$ foram as espécies que mais se destacaram na amostragem (tabela 3). Inga vera possuiu menor densidade absoluta (200 ind ha $\left.{ }^{-1}\right)$, porém, maior dominância absoluta $(8,77$ $\left.\mathrm{m}^{2} \mathrm{ha}^{-1}\right)$ do que Guarea macrophylla $\left(262,04\right.$ ind ha ${ }^{-1}$; $4,98 \mathrm{~m}^{2} \mathrm{ha}^{-1}$ ), o que justifica seu maior VI. Juntas, essas três espécies representam 53,9\% do VI total da área, o que explica o baixo valor de $\mathrm{J}(0,601)$. $\mathrm{O}$ valor de $\mathrm{H}^{\text {' }}$ obtido para a área foi considerado baixo: 2,36 nats ind ${ }^{-1}$. 
Martins (1993), com base em diversos trabalhos, considerou que, para a Mata Atlântica, o H' varia entre 3,61 e 4,07, em florestas não inundáveis. Em um estudo em área aluvial no Município de Madre de Deus de Minas, MG, Vilela et al. (2000) também observaram baixa diversidade de espécies ( $\mathrm{H}^{\prime}$ de 0,93 nats ind $\left.{ }^{-1}\right)$ e uma alta dominância de Salix humboldtiana e Inga vera (J de 0,45). Essa alta dominância e baixa diversidade estão associadas ao ambiente restritivo e seletivo, favorecendo poucas espécies adaptadas a estas condições (Rocha et al. 2005, van den Berg et al. 2006, Vilela et al. 2000).

Verifica-se que a maioria dos indivíduos de Inga vera, ao contrário de Sebastiania commersoniana e Guarea macrophylla, está concentrada nas Classes 2 e

Tabela 3. Espécies arbóreas (DAP $\geq 5 \mathrm{~cm}$ ) encontradas nas 54 parcelas alocadas nos fragmentos de floresta aluvial e na mata ciliar no Município de São Sebastião da Bela Vista, MG, ordenadas pelo VI. (H = altura máxima de cada espécie (m); DA = densidade absoluta (ind ha $\left.{ }^{-1}\right)$; DR = densidade relativa (\%); DoA = dominância absoluta $\left(\mathrm{m}^{2} \mathrm{ha}^{-1}\right)$; DoR = dominância relativa (\%); FA = frequiência absoluta $(\%) ; \mathrm{FR}=$ freqüência relativa (\%); VI = valor de importância (\%).)

Table 3. Tree species (DAP $\geq 5 \mathrm{~cm}$ ) sampled in 54 plots allocated in the alluvial fragments forest and riparian forests in the municipality of São Sebastião da Bela Vista, MG, Brazil, ranked by VI. (H = Maximum height of each species (m); DA = absolute density $\left(\right.$ ind ha $\left.{ }^{-1}\right) ; \mathrm{DR}=$ relative density $(\%)$; DoA $=$ absolute dominance $\left(\mathrm{m}^{2} \mathrm{ha}^{-1}\right) ; \mathrm{DoR}=$ relative dominance $(\%)$; $\mathrm{FA}=$ absolute frequency $(\%) ; \mathrm{FR}=$ relative frequency $(\%) ; \mathrm{VI}=$ importance value $(\%)$.)

\begin{tabular}{|c|c|c|c|c|c|c|c|c|c|}
\hline Espécie & Abrev. & $\mathrm{H}$ & $\mathrm{DA}$ & DR & DoA & DoR & FA & FR & VI \\
\hline Sebastiania commersoniana & Seba com & 17 & 791,67 & 41,42 & 13,48 & 32,337 & 96,30 & 11,30 & 28,36 \\
\hline Inga vera & Inga ver & 25 & 200,00 & 10,47 & 8,77 & 21,051 & 79,63 & 9,35 & 13,62 \\
\hline Guarea macrophylla & Guar mac & 17 & 262,04 & 13,71 & 4,98 & 11,940 & 85,19 & 10,00 & 11,88 \\
\hline Casearia sylvestris & Case syl & 15 & 86,11 & 4,51 & 1,31 & 3,143 & 42,59 & 5,00 & 4,22 \\
\hline Alchornea triplinervia & Alch tri & 20 & 58,33 & 3,05 & 1,51 & 3,627 & 35,19 & 4,13 & 3,60 \\
\hline Nectandra nitidula & Nect nit & 11 & 66,67 & 3,49 & 1,06 & 2,555 & 35,19 & 4,13 & 3,39 \\
\hline Pouteria gardneriana & Pout gar & 18 & 19,44 & 1,02 & 2,36 & 5,673 & 27,78 & 3,26 & 3,32 \\
\hline Eugenia florida & Euge flo & 20 & 29,63 & 1,55 & 0,78 & 1,864 & 44,44 & 5,22 & 2,88 \\
\hline Copaifera langsdorffii & Copa lan & 25 & 21,30 & 1,11 & 1,84 & 4,427 & 18,52 & 2,17 & 2,57 \\
\hline Vitex megapotamica & Vite meg & 20 & 23,15 & 1,21 & 0,88 & 2,114 & 27,78 & 3,26 & 2,20 \\
\hline Rollinia emarginata & Roll ema & 12 & 28,70 & 1,50 & 0,30 & 0,727 & 37,04 & 4,35 & 2,19 \\
\hline Nectandra megapotamica & Nect meg & 14 & 27,78 & 1,45 & 1,43 & 3,434 & 12,96 & 1,52 & 2,14 \\
\hline Croton urucurana & Crot uru & 15 & 26,85 & 1,41 & 0,35 & 0,828 & 24,07 & 2,83 & 1,69 \\
\hline Picramnia sellowii & Picr sel & 7 & 27,78 & 1,45 & 0,09 & 0,223 & 24,07 & 2,83 & 1,50 \\
\hline Trichilia pallida & Tric pal & 15 & 17,59 & 0,92 & 0,32 & 0,774 & 18,52 & 2,17 & 1,29 \\
\hline Eugenia sp. & Euge sp & 7 & 14,81 & 0,78 & 0,09 & 0,211 & 18,52 & 2,17 & 1,05 \\
\hline Symplocos tetrandra & Symp tet & 18 & 24,07 & 1,26 & 0,21 & 0,511 & 11,11 & 1,30 & 1,03 \\
\hline Eugenia dodonaeaefolia & Euge dod & 16 & 15,74 & 0,82 & 0,16 & 0,385 & 12,96 & 1,52 & 0,91 \\
\hline Myrsine gardneriana & Myrs gar & 15 & 9,26 & 0,48 & 0,07 & 0,171 & 16,67 & 1,96 & 0,87 \\
\hline Symplocos uniflora & Symp uni & 10 & 21,30 & 1,11 & 0,16 & 0,387 & 9,26 & 1,09 & 0,86 \\
\hline Calyptranthes widgreniana & Caly wid & 8 & 16,67 & 0,87 & 0,07 & 0,162 & 11,11 & 1,30 & 0,78 \\
\hline Myrcia pulchra & Myrc pul & 9 & 11,11 & 0,58 & 0,10 & 0,233 & 12,96 & 1,52 & 0,78 \\
\hline Maytenus salicifolia & Mayt sal & 12 & 11,11 & 0,58 & 0,04 & 0,101 & 12,96 & 1,52 & 0,73 \\
\hline Cupania ludowigii & Cupa lud & 15 & 5,56 & 0,29 & 0,13 & 0,311 & 9,26 & 1,09 & 0,56 \\
\hline Myrcia oblongata & Myrc obl & 11 & 11,11 & 0,58 & 0,09 & 0,215 & 7,41 & 0,87 & 0,56 \\
\hline Myrciaria tenella & Myrc ten & 7 & 5,56 & 0,29 & 0,03 & 0,081 & 9,26 & 1,09 & 0,49 \\
\hline Xylosma venosa & Xylo ven & 9 & 5,56 & 0,29 & 0,03 & 0,081 & 9,26 & 1,09 & 0,49 \\
\hline Duguetia lanceolata & Dugu lan & 20 & 6,48 & 0,34 & 0,19 & 0,462 & 5,56 & 0,65 & 0,48 \\
\hline Andira vermifuga & Andi ver & 11 & 4,63 & 0,24 & 0,04 & 0,094 & 9,26 & 1,09 & 0,47 \\
\hline Syagrus romanzoffiana & Syag rom & 15 & 6,48 & 0,34 & 0,15 & 0,361 & 5,56 & 0,65 & 0,45 \\
\hline
\end{tabular}


continuação

\begin{tabular}{llrrrrrrrr}
\hline Espécie & Abrev. & H & DA & DR & DoA & DoR & FA & FR & VI \\
\hline Myrcia undulata & Myrc und & 9,5 & 10,19 & 0,53 & 0,05 & 0,127 & 5,56 & 0,65 & 0,44 \\
Cecropia pachystachya & Cecr pac & 16 & 5,56 & 0,29 & 0,12 & 0,296 & 5,56 & 0,65 & 0,41 \\
Eugenia cf myrciariifolia & Euge myr & 11 & 4,63 & 0,24 & 0,03 & 0,084 & 7,41 & 0,87 & 0,40 \\
Guettarda viburnoides & Guet vib & 5 & 3,70 & 0,19 & 0,03 & 0,075 & 7,41 & 0,87 & 0,38 \\
Eugenia blastantha & Euge bla & 7 & 3,70 & 0,19 & 0,01 & 0,033 & 7,41 & 0,87 & 0,37 \\
Calycorectes psidiiflorus & Cary psi & 9,5 & 4,63 & 0,24 & 0,01 & 0,029 & 5,56 & 0,65 & 0,31 \\
Myrcia multiflora & Myrc mul & 7 & 2,78 & 0,15 & 0,01 & 0,026 & 5,56 & 0,65 & 0,27 \\
Erythrina falcata & Eryt fal & 17 & 0,93 & 0,05 & 0,19 & 0,464 & 1,85 & 0,22 & 0,24 \\
Daphnopsis fasciculata & Daph fas & 8 & 2,78 & 0,15 & 0,02 & 0,040 & 3,70 & 0,43 & 0,21 \\
Ocotea indecora & Ocot ind & 10 & 1,85 & 0,10 & 0,04 & 0,085 & 3,70 & 0,43 & 0,21 \\
Xylosma prockia & Xylo pro & 8 & 1,85 & 0,10 & 0,02 & 0,050 & 3,70 & 0,43 & 0,19 \\
Capsicodendron dinisii & Caps din & 10 & 1,85 & 0,10 & 0,01 & 0,026 & 3,70 & 0,43 & 0,19 \\
Plinia cauliflora & Plin cau & 6 & 1,85 & 0,10 & 0,01 & 0,018 & 3,70 & 0,43 & 0,18 \\
Myrcia laruotteana & Myrc lar & 6 & 1,85 & 0,10 & 0,00 & 0,010 & 3,70 & 0,43 & 0,18 \\
Campomanesia guaviroba & Camp gua & 15 & 0,93 & 0,05 & 0,02 & 0,057 & 1,85 & 0,22 & 0,11 \\
Cryptocarya saligna & Cryp sal & 12 & 0,93 & 0,05 & 0,02 & 0,037 & 1,85 & 0,22 & 0,10 \\
Sorocea bonplandii & Soro bon & 10 & 0,93 & 0,05 & 0,01 & 0,015 & 1,85 & 0,22 & 0,09 \\
Miconia paulensis & Mico pau & 8 & 0,93 & 0,05 & 0,01 & 0,014 & 1,85 & 0,22 & 0,09 \\
Andira fraxinifolia & Andi fra & 6 & 0,93 & 0,05 & 0,01 & 0,012 & 1,85 & 0,22 & 0,09 \\
Lacistema hasslerianum & Laci has & 2,5 & 0,93 & 0,05 & 0,00 & 0,010 & 1,85 & 0,22 & 0,09 \\
Ficus luschnathiana & Ficu lus & 5,5 & 0,93 & 0,05 & 0,00 & 0,007 & 1,85 & 0,22 & 0,09 \\
\hline Total & & 25 & 1911,11 & 100,00 & 41,67 & 100,00 & 851,85 & 100,0 & 100,0 \\
\hline
\end{tabular}

3 de diâmetro, entre os diâmetros de 9 a $32,9 \mathrm{~cm}$, tendo distribuição próxima da normal (figura 2). Inga vera é também, entre as espécies estudadas, a que possuiu mais indivíduos na Classe 4 de diâmetro (17 a 32,9 cm), indicando indivíduos maiores na área, como já demonstrado pela área basal (tabela 3).

Quando há grande número de indivíduos jovens em relação a indivíduos adultos, a população está estável e provavelmente crescendo, porém, poucos indivíduos jovens podem indicar que a população está em declínio, pois não há regeneração natural suficiente, que pode ser característica da espécie ou, como muitas vezes ocorre, influência da intervenção antrópica (Condit et al. 1998). Porém, Schaaf et al. (2006) concluíram, em seus estudos, que o grande número de indivíduos nas classes inferiores de diâmetro nem sempre é um indicativo de que a espécie irá manter uma população viável.

Uma espécie com poucos indivíduos nas classes inferiores de diâmetro, mas com pequena probabilidade de morrer devido à competição, provavelmente se manterá na floresta, enquanto que uma espécie com grande parte dos indivíduos sujeitos a morrer, devido à competição, necessita apresentar uma grande freqüência nas classes diamétricas inferiores para ter alguma chance de sobreviver na comunidade. Assim, pode-se concluir que a distribuição diamétrica reflete as características autoecológicas das espécies (Schaaf et al. 2006).

Em toda área, além de Inga vera, as outras espécies que ocupam o estrato superior do dossel $(\mathrm{h} \geq 20 \mathrm{~m})$ são: Alchornea triplinervia, Eugenia florida, Vitex megapotamica, Duguetia lanceolata e Copaifera langsdorffii (tabela 3). As espécies que ocorrem somente no sub-bosque (h < 8 m) são: Picramnia sellowii, Eugenia sp., Myrciaria tenella, Guettarda viburnoides, Eugenia blastantha, Myrcia multiflora, Plinia cauliflora, Myrcia laruotteana, Andira fraxinifolia, Lacistema hasslerianum e Ficus luschnathiana. Considerando a distribuição diamétrica da comunidade, constatou-se tendência ao padrão J invertido (figura 2), não sendo um J invertido típico, provavelmente devido ao aumento crescente dos intervalos de diâmetro abrangidos pelas classes. Em populações importantes dentro da comunidade, como as de Sebastiania commersoniana e Inga vera, não foi observada esta estrutura, pois houve menos indivíduos de menores diâmetros, o que pode ser devido à característica ecológica da espécie ou à fatores ambientais. Apenas 

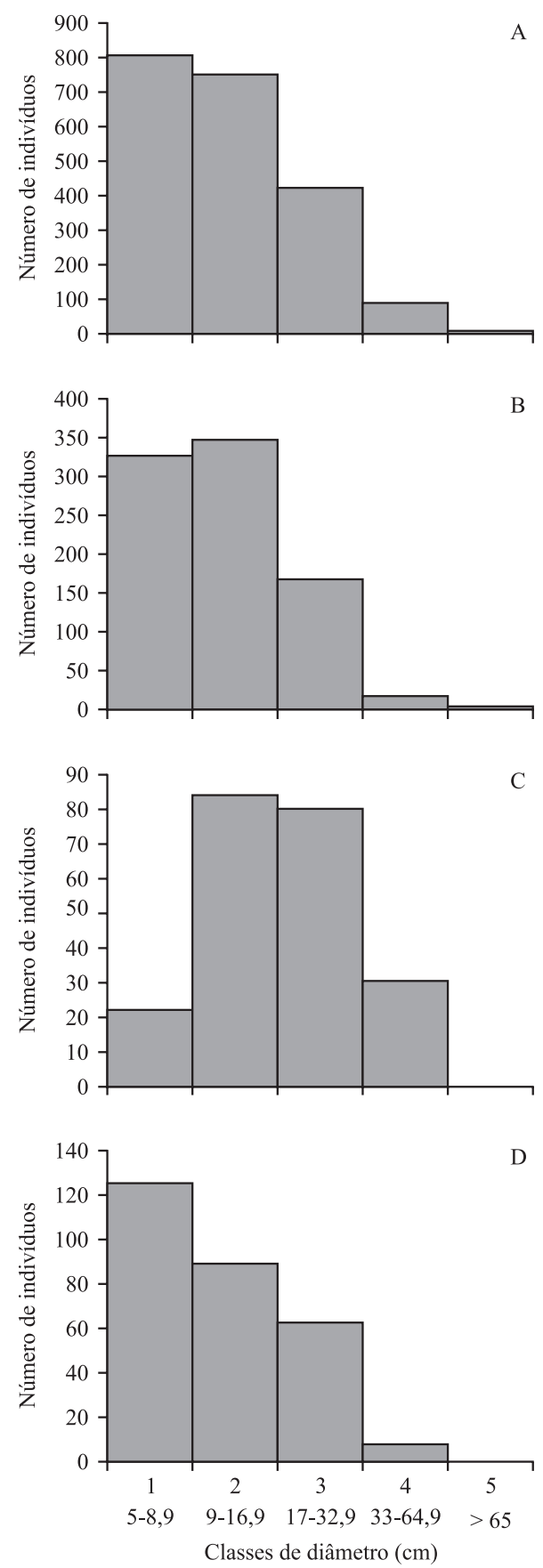

Figura 2. Estrutura diamétrica da amostragem total (A) e das três espécies com maior dominância - Sebastiania commersoniana (B), Inga vera (C) e Guarea macrophylla (D) - nas 54 parcelas alocadas em uma mata ciliar e em cinco fragmentos de floresta aluvial localizados no Município de São Sebastião da Bela Vista, MG.

Figure 2. Diameter structure for the total sample (A) and for the three most dominant species - Sebastiania commersoniana (B), Inga vera (C) e Guarea macrophylla (D) - in 54 plots allocated in the riparian forest and in the five alluvial forest fragments in the municipality of São Sebastião da Bela Vista, MG, Brazil.
Guarea macrophylla, dentre as espécies com maior VI, apresentou população com tendência ao J invertido (figura 2).

Verifica-se a tendência de padrão $J$ invertido no componente arbóreo de alguns fragmentos, porém, na mata ciliar, houve distribuição diamétrica com maior número de indivíduos nas Classes 2 e 3 de diâmetro (9$32,9 \mathrm{~cm}$ ), tendendo à distribuição de normal (figura 3). Inga vera contribuiu pouco para a tendência à distribuição normal, pois, apesar de a mata ciliar possuir grandes indivíduos desta espécie, estes representam apenas 63 dos 650 indivíduos presentes na área. Além disso, a mata ciliar possui o mesmo padrão de dominância ecológica de toda área, com mais indivíduos de Sebastiania commersoniana, seguida por Guarea macrophylla.

Na mata ciliar, ao contrário dos fragmentos, o nível freático ficou abaixo de $1 \mathrm{~m}$ de profundidade do solo durante todas as medições nos poços de observação. Porém, há evidências de alagamentos temporários provocados por enchentes, como a presença de sedimentos sobre plântulas durante a época de maior pluviosidade. Nesses locais, onde o processo de sedimentação e a grande velocidade do rio dificultam o estabelecimento de plântulas, a regeneração natural pode ser menor, o que, provavelmente, é uma das causas da menor ocorrência de indivíduos de pequeno porte, ressaltando-se, porém, que os menores indivíduos avaliados neste estudo possuem $5 \mathrm{~cm}$ de DAP.

Segundo Rodrigues \& Shepherd (2000), a inundação ocorrente na faixa ciliar é instrumento natural de perturbação da vegetação, pois o extravasamento do rio provoca o soterramento ou remoção periódica da serapilheira, do banco de sementes e mortalidade de plântulas, dificultando a regeneração natural.

Distribuição das espécies - Os autovalores da CCA para os três primeiros eixos de ordenação foram de 0,270 (eixo 1), 0,221 (eixo 2) e 0,113 (eixo 3). Autovalores baixos (<0,5 sensu ter Braak 1995) indicam a existência de gradiente curto, com baixa substituição de espécies entre extremos e predominância de variações na abundância das espécies. Os três primeiros eixos explicaram apenas $23,7 \%$ da variância dos dados (eixo $1=10,6 \%$, eixo $2=8,7 \%$ e eixo $3=4,4 \%$ ), indicando grande variância remanescente não explicada pelas variáveis ambientais utilizadas. No entanto, isso é comum em dados de vegetação e não prejudica a significância das relações espécie-ambiente (ter Braak 1987), mesmo porque os três primeiros eixos de ordenação obtiveram altas correlações de Pearson (0,908, eixo 1, 0,815, eixo 2 e 0,795, eixo 3) e o teste de permutação de Monte Carlo indicou correlações significativas para os três eixos 
$(P=0,01)$ entre abundância das espécies e variáveis ambientais. As variáveis ambientais mantidas na CCA por possuírem correlações altas com os dois primeiros eixos de ordenação $(r<0,5)$ foram: teores de $\mathrm{Mg}, \mathrm{H}+\mathrm{Al}$ e MO, porcentagem de areia, silte e argila no solo, nível freático no mês de maior encharcamento e cobertura do dossel. As variáveis com correlações fracas com os dois primeiros eixos da CCA, como o impacto ambiental, não explicaram de forma significativa a distribuição das espécies na área. As variáveis mais correlacionadas com o primeiro eixo foram teores de matéria orgânica, teores de $\mathrm{H}+\mathrm{Al}$, profundidade do nível freático no solo e porcentagem de argila (tabela 4). A variável ambiental mais correlacionada com o segundo eixo foi cobertura do dossel.

Foram altas e positivas as correlações ponderadas entre teor de matéria orgânica, teores de $\mathrm{H}+\mathrm{Al}$, altura máxima do nível freático e teor de argila (tabela 4). Já o teor de areia teve correlação negativa com todas essas variáveis. Isso ocorreu devido à presença de dois extremos ambientais ocasionados pelos processos geomorfológicos
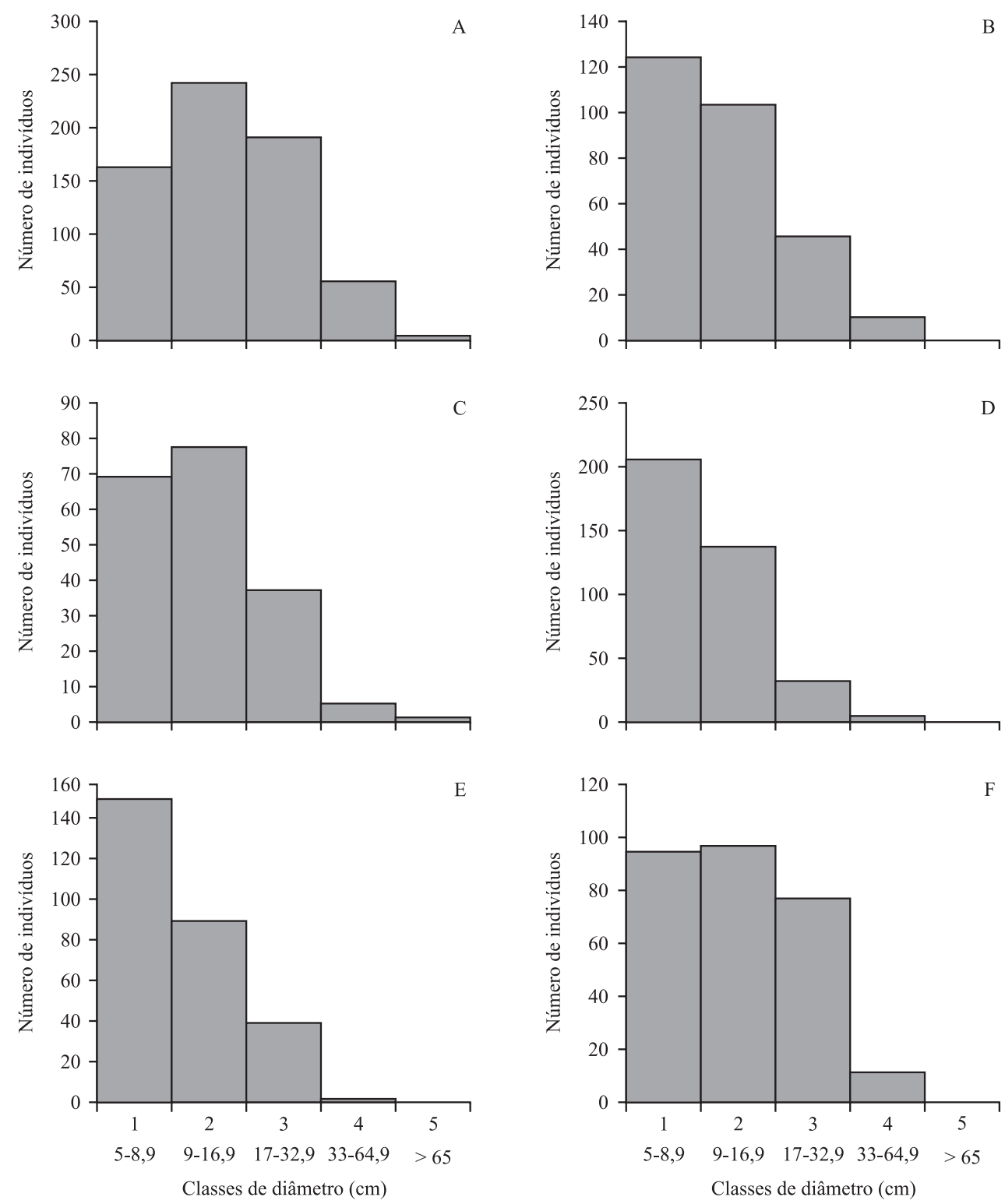

Figura 3. Estrutura diamétrica da amostragem do componente arbóreo da mata ciliar (A) e dos fragmentos 1 (B), 2 (C), 3 (D), 4 (E) e 5 (F) de floresta aluvial localizados no Município de São Sebastião da Bela Vista, MG.

Figure 3. Diameter structure for the tree component sampled in the riparian forest (A) and in fragments 1 (B), 2 (C), 3 (D), 4 (E) and 5 (F) of alluvial forest located in the municipality of São Sebastião da Bela Vista, MG, Brazil. 
Tabela 4. Análise de correspondência canônica (CCA): correlações internas ('intraset') nos três primeiros eixos de ordenação e matriz de correlações ponderadas para as variáveis ambientais mensuradas em 54 parcelas alocadas em uma mata ciliar e em cinco fragmentos de floresta aluvial no Município de São Sebastião da Bela Vista, MG. Correlações com valores absolutos $>0,5$ ou $<-0,5$ estão indicadas em negrito.

Table 4. Canonical correspondence analysis (CCA): internal correlation ('intraset') in the first three ordination axes and weighed correlation matrix for the environmental variables measured in 54 plots allocated in riparian and alluvial forest fragments in the municipality of São Sebastião da Bela Vista, MG, Brazil. Correlation with absolute values $>0,5$ or $<-0,5$ are indicated in bold.

\begin{tabular}{lrrrrrrrrc}
\hline \multirow{2}{*}{ Variáveis ambientais } & \multirow{2}{*}{ Eixo 1 } & \multirow{2}{*}{ Eixo 2 } & \multicolumn{7}{c}{ Correlações ponderadas } \\
\cline { 6 - 10 } & & & $\mathrm{Mg}$ & $\mathrm{H}+\mathrm{Al}$ & Mat. Org. & Areia & Silte & Argila & Nível freático \\
\hline $\mathrm{Mg}$ & $\mathbf{0 , 5 7 6}$ & 0,029 & - & - & - & - & - & - & - \\
$\mathrm{H}+\mathrm{Al}$ & $\mathbf{- 0 , 9 0 5}$ & 0,052 & $-0,486$ & - & - & - & - & - & - \\
Matéria orgânica & $\mathbf{- 0 , 9 8 4}$ & 0,009 & $-0,461$ & $\mathbf{0 , 8 7 3}$ & - & - & - & - & - \\
Areia & $\mathbf{0 , 6 9 2}$ & $-0,068$ & 0,435 & $\mathbf{- 0 , 7 8 2}$ & $\mathbf{- 0 , 6 5 9}$ & - & - & - & - \\
Silte & 0,499 & $\mathbf{0 , 5 4 2}$ & 0,467 & $-0,291$ & $-0,445$ & 0,119 & - & - & - \\
Argila & $\mathbf{0 , 8 0 9}$ & $-0,219$ & $\mathbf{- 0 , 5 8 6}$ & $\mathbf{0 , 7 7 6}$ & $\mathbf{0 , 7 5 5}$ & $\mathbf{- 0 , 8 6 5}$ & $\mathbf{- 0 , 6 0 2}$ & - & - \\
Nível freático & $\mathbf{- 0 , 8 7 1}$ & 0,402 & $-0,431$ & $\mathbf{0 , 7 6 8}$ & $\mathbf{0 , 8 5 2}$ & $\mathbf{- 0 , 6 1 4}$ & $-0,338$ & $\mathbf{0 , 6 6 5}$ & - \\
Cobertura do dossel & $\mathbf{0 , 5 0 9}$ & $\mathbf{- 0 , 6 3 0}$ & 0,307 & $\mathbf{- 0 , 5 6 3}$ & $\mathbf{- 0 , 5 1 7}$ & 0,479 & 0,030 & $-0,401$ & $\mathbf{- 0 , 6 6 6}$ \\
\hline
\end{tabular}

da dinâmica de sedimentação da área. Durante as cheias do rio, pode ocorrer seu extravasamento e sedimentos são depositados na mata ciliar ou levados a distâncias maiores, na planície após o trecho de mata, onde estão localizados os fragmentos. Os sedimentos maiores e mais pesados (predominantemente arenosos) são depositados mais próximo do rio, no dique marginal da mata ciliar, enquanto que os sedimentos mais finos e leves (predominantemente argilosos) são carregados, pelas águas das cheias, a uma distância maior do rio (fragmentos na planície aluvial) (Ab’Saber 2000). Os resultados encontrados confirmam este padrão, pois foram encontrados solos mais argilosos nos fragmentos e solos mais arenosos na mata ciliar (tabela 1).

A maior porcentagem de argila no solo dificulta a infiltração de água, colaborando para a sua retenção e formando solos saturados, como os encontrados nos fragmentos. Com a baixa disponibilidade de oxigênio nestes solos, não há suficiente decomposição da matéria orgânica, ocorrendo seu acúmulo e ocasionando o aumento da acidez do solo (maior disponibilidade de H). Ao contrário, os solos da mata ciliar, mais arenosos em comparação com os dos fragmentos, possuem maior eficiência da infiltração de água, não proporcionando sua retenção e nem a acumulação de matéria orgânica. Em outros estudos, como o de van den Berg et al. (2006), a textura do solo foi também um importante fator condicionante da distribuição das espécies na floresta aluvial localizada na bacia do Rio Preto (pertencente à bacia do Rio Grande), Sul de Minas Gerais.

Foi possível constatar, na CCA, a separação de grupos de parcelas de acordo com a distribuição das espécies, associada ao ambiente no qual se encontram (figura 4). Em relação ao primeiro eixo, da esquerda para a direita do gráfico, houve o aumento dos valores de teor de $\mathrm{Mg}$, porcentagem de areia e profundidade do nível freático (redução do nível freático) e diminuição dos teores de $\mathrm{MO}, \mathrm{H}+\mathrm{Al}$ e argila. À esquerda predominaram parcelas com Gleissolos Melânicos (parcelas 25 a 27, 29, 37 a 54), associados à maior saturação hídrica e, à direita, parcelas com Neossolos Flúvicos (parcelas 1 a 24) e Cambissolos (parcelas 28, 30 e 31 a 36), que são mais bem drenados (figura 4A).

Symplocos tetrandra, Symplocos uniflora, Vitex megapotamica, Myrcia oblongata, Myrcia pulchra, Eugenia sp., Alchornea triplinervia, Myrsine gardneriana, Croton urucurana e Xylosma venosa ocorreram com maior frequiência nos Gleissolos, com maior saturação hídrica (figura 4B). Nectandra megapotamica, Casearia sylvestris, Cecropia pachystachya, Myrciaria tenella, Guarea macrophylla, Pouteria gardneriana e Eugenia florida ocorreram mais frequientemente nos ambientes mais bem drenados, nos Neossolos e Cambissolos. Sebastiania commersoniana e Inga vera, espécies muito comuns em toda a área, ocorreram tanto em ambientes mais como em menos 


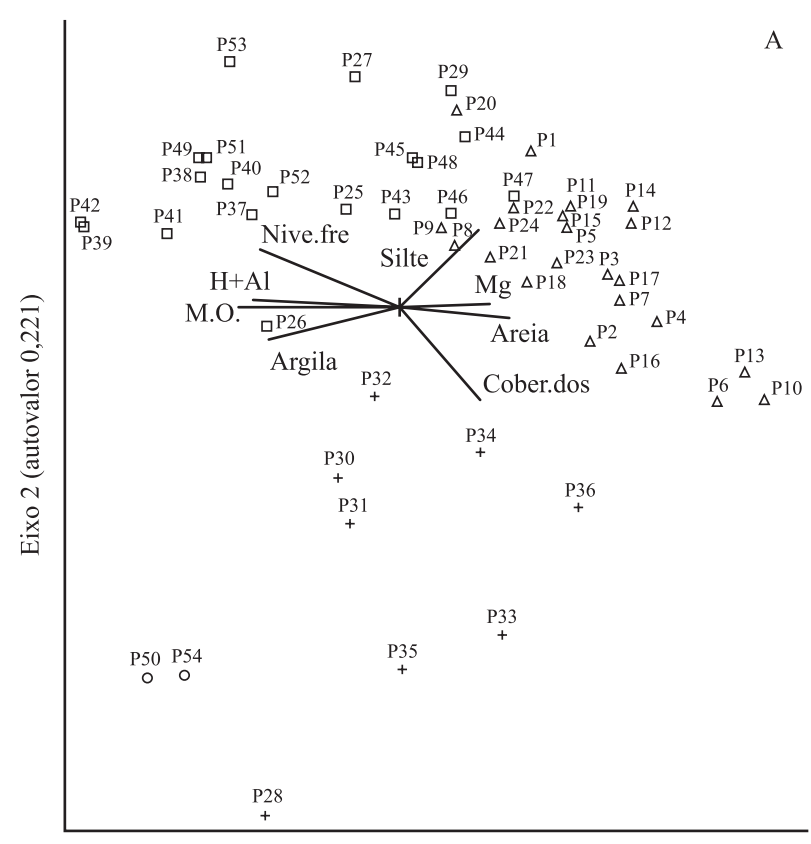

Eixo 1 (autovalor 0,270)

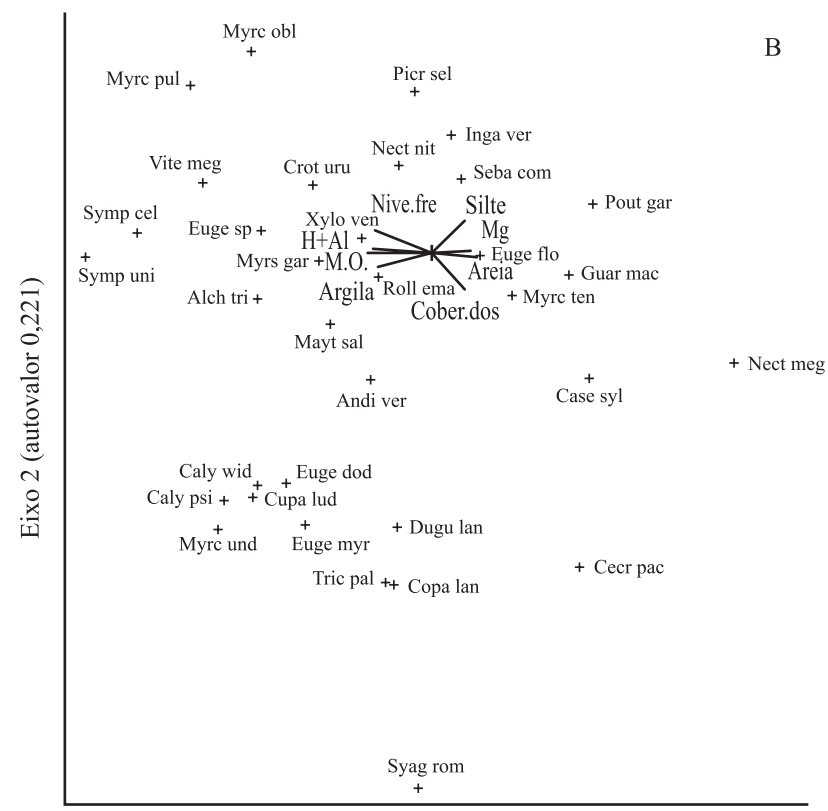

Eixo 1 (autovalor 0,270)

Figura 4. Distribuição das parcelas estudadas (A) e das espécies (B) na análise de correspondência canônica (CCA) realizada para as 54 parcelas alocadas em uma mata ciliar e em cinco fragmentos de floresta aluvial no Município de São Sebastião da Bela Vista, MG. As variáveis utilizadas foram: porcentagem de argila (Argila), porcentagem da areia (Areia), porcentagem de silte (Silte), teor de matéria orgânica (MO), teores de hidrogênio e alumínio $(\mathrm{H}+\mathrm{Al})$, teor de magnésio $(\mathrm{Mg})$, nível freático no solo (Nive.fre) e cobertura do dossel (Cober.dos). (Solos: $\Delta=$ Neossolos Flúvicos Tb distróficos câmbicos; $\square=$ Gleissolos Melânicos distróficos hísticos; + = Cambissolos Húmicos Tb distróficos gleicos; $\mathrm{O}=$ Gleissolos Melânicos distróficos típicos, abreviatura das espécies estão na tabela 3. inundados, neste estudo. Porém, outros autores encontram estas espécies em ambientes com maior saturação hídrica: Vilela et al. (2000) encontraram Inga vera e Botrel et al. (2002) e Pereira et al. (2006) encontraram Sebastiania commersoniana. Casearia sylvestris também foi descrita por Araujo et al. (2004), como espécie mais comum em locais com nível freático mais profundo, confirmando os resultados deste estudo, porém, Botrel et al. (2002) encontraram-na mais frequientemente em ambiente com maior saturação hídrica, juntamente com Nectandra megapotamica que, neste estudo, foi mais frequiente em ambiente com menor saturação hídrica. Croton urucurana foi também encontrado em ambientes com maior saturação hídrica por Vilela et al. (2000) e Botrel et al. (2002), e Vitex megapotamica por Pereira et al. (2006).

Em relação ao segundo eixo da CCA, parcelas alocadas nos Cambissolos (28, 30 e 31 a 36) e nos Gleissolos Melânicos Distróficos Típicos (50 e 54) ficaram abaixo no gráfico, separadas das demais, o que pode ser explicado pelas duas variáveis mais importantes do eixo 2: cobertura do dossel e porcentagem de silte (figura 4A). De cima para baixo no eixo 2 do gráfico de ordenação, ocorre a diminuição da porcentagem de silte e aumento da cobertura do dossel (figura 4). Nas parcelas de Cambissolos houve menor porcentagem de silte (tabela 1), confirmando os resultados encontrados na CCA. A porcentagem de silte nos Gleissolos é de 28,59\% (tabela 1), sendo que GMdh possui 29,15\% de silte e GMdt $23,0 \%$, um dos fatores que ocasionaram a separação das parcelas dos dois tipos de Gleissolos (GMdh e GMdt) no eixo 2 da CCA (figura 4A).

Os dosséis com maior cobertura foram o da mata ciliar (Neossolos) e os das parcelas alocadas em Cambissolos. A vegetação das parcelas alocadas nos Gleissolos possui dossel mais aberto, provavelmente devido à maior saturação hídrica do solo, o que pode estar ocasionando maior deciduidade das folhas. Adeficiência

Figure 4. Distribution of the studied plots (A) and species (B) in the canonical correspondence analysis (CCA) conducted for the 54 plots allocated in the riparian forest and in the five alluvial forest fragments in the municipality of São Sebastião da Bela Vista, MG, Brazil. The variables used were: percentage of clay (Argila), sand (Areia) and silt (Silte), content of organic matter (MO), hydrogen and aluminum $(\mathrm{H}+\mathrm{Al})$, magnesium $(\mathrm{Mg})$, soil water table level (Nive.fre) and canopy coverage (Cober.dos). (Soils: $\Delta=$ Neosols Fluvic Tb dystrophic cambic; $\square=$ Gleysols Melanic dystrophic histic; + = Cambisols Humic Tb dystrophic gley; $\mathrm{O}=$ Gleysols Melanic dystrophic typic, species abbreviaton are in table 3 . 
de $\mathrm{O}_{2}$ no solo em áreas com saturação hídrica causa aumento da resistência radicular, reduzindo a absorção de água e, em conseqüência disso, plantas adaptadas a estes ambientes sobrevivem por meio do fechamento estomático (Lobo \& Joly 2000) ou abcisão das folhas, mecanismos que evitam a perda de água para a atmosfera.

O presente trabalho confirma o padrão observado em florestas aluviais, de baixa diversidade de espécies arbóreas e elevada dominância ecológica. Também aponta para a importância das variações do nível freático do solo na diferenciação da estrutura do componente arbóreo em pequena escala.

A heterogeneidade ambiental, representada principalmente por fatores edáficos químicos, texturais e de altura do nível freático, ocasionou variações florísticas e estruturais nos fragmentos estudados. Os dois principais extremos ambientais, localizados na mata ciliar, de solos mais arenosos e com nível freático distante da superfície, e em alguns fragmentos de nível freático mais próximo à superfície, com maior porcentagem de argila, matéria orgânica e acidez nos solos, foram determinantes na separação de grupos de parcelas, de acordo com a distribuição das espécies na área, tendo algumas demonstrado maior ou menor ocorrência nos diferentes ambientes.

Agradecimentos - Ao pesquisador Marcos Eduardo Guerra Sobral, pela identificação das espécies da família Myrtaceae.

\section{Referências bibliográficas}

AB'SABER, A.N. 2000. O suporte geoecológico das florestas beiradeiras (ciliares). In Matas ciliares: conservação e recuperação (R.R. Rodrigues \& H.F. Leitão Filho, eds.). Edusp, São Paulo, p.15-25.

APG II. 2003. An update of the Angiosperm Phylogeny Group classification for the orders and families of flowering plants: APG II. Botanical Journal of the Linnean Society 141:399-436.

ARAUJO, M.M., LONGHI, S.J., BRENA, D.A., BARROS, P.L.C. \& FRANCO, S. 2004. Análise de agrupamento da vegetação de um fragmento de floresta estacional decidual aluvial, Cachoeira do Sul, RS, Brasil. Ciência Florestal 14:133-147.

BARDDAL, M.L., RODERJAN, C.V., GALVÃO, F. \& CURCIO, G.R. 2004. Caracterização florística e fitossociológica de um trecho sazonalmente inundável de floresta aluvial, em Araucária, PR. Ciência Florestal 14:37-50.

BARRELLA, W., PETRERE JÚNIOR, M., SMITH, W.S. \& MONTAG, L.F.A. 2000. As relações entre as matas ciliares, os rios e os peixes. In Matas ciliares: conservação e recuperação (R.R. Rodrigues \& H.F. Leitão Filho, eds.). Edusp, São Paulo, p.187-207.
BOTREL, R., OLIVEIRA-FILHO, A.T., RODRIGUES, L.A. \& CURI, N. 2002. Influência do solo e topografia sobre as variações da composição florística e estrutura da comunidade arbóreo-arbustiva de uma floresta estacional semidecidual em Ingaí, MG. Revista Brasileira de Botânica 25:195-213.

BRASIL. 1992. Normais climatológicas 1961-1990. Ministério da Agricultura e Reforma Agrária, Brasília.

BROWER, J.E. \& ZAR, J.H. 1984. Field and laboratory methods for general ecology. W.M.C. Brow, Dubuque.

BRUMMITT, R.K. \& POWELL, C.E. 1992. Authors of plant names. Royal Botanic Gardens, Kew.

CONDIT, R., SUKUMAR, R., HUBBELL, S.P. \& FOSTER, R.B. 1998. Predicting population trends from size distributions: a direct test in a tropical tree community. The American Naturalist 152:495-509.

EMBRAPA. 1997. Manual de métodos de análises de solo. 2ae ed. Empresa Brasileira de Pesquisa Agropecuária, Rio de Janeiro.

EMBRAPA. 1999. Sistema brasileiro de classificação de solos. Empresa Brasileira de Pesquisa Agropecuária, Rio de Janeiro.

HELTSCHE, J.F. \& FORRESTER, N.E. 1983. Estimating species richness using the jackknife procedure. Biometrics 39:1-12.

IBGE. 1992. Manual técnico da vegetação brasileira. Série: Manuais técnicos em geociências n.1. Fundação Instituto Brasileiro de Geografia e Estatística, Rio de Janeiro.

IVANAUSKAS, N.M. 2002. Estudo da vegetação presente na área de contato entre formações florestais em Gaúcha do Norte - MT. Tese de doutorado, Universidade Estadual de Campinas, Campinas.

LINO, C.F. \& DIAS, H. 2003. Águas e florestas da Mata Atlântica: por uma gestão integrada. Conselho Nacional da Reserva da Biosfera da Mata Atlântica e Fundação S.O.S. Mata Atlântica. Programa Águas e Florestas da Mata Atlântica, São Paulo.

LOBO, P.C. \& JOLY, C.A. 2000. Aspectos ecofisiológicos da vegetação de mata ciliar do Sudeste do Brasil. In Matas ciliares: conservação e recuperação (R.R. Rodrigues \& H.F. Leitão Filho, eds.). Edusp, São Paulo, p.143-157.

LOURES, L. 2006. Variações florísticas e estruturais em um fragmento de floresta paludosa, no Alto-Rio Pardo, em Santa Rita de Caldas, MG. Dissertação de mestrado, Universidade Federal de Lavras, Lavras.

MARTINS, F.R. 1993. Estrutura de uma floresta mesófila. 2a ed. Editora da Unicamp, Campinas.

MEIRA-NETO, J.A.A., SOUZA, A.L., SILVA, A.F. \& PAULA, A. 1997. Estrutura de uma floresta estacional semidecidual aluvial em área diretamente afetada pela usina hidrelétrica de Pilar, Ponte Nova, Zona da Mata de Minas Gerais. Revista Árvore 21:213-219. 
MEIRA-NETO, J.A.A., RÊGO, M.M., COELHO, D.J.S. \& RIBEIRO, F.G. 2003. Origem, sucessão e estrutura de uma floresta de galeria periodicamente alagada em Viçosa-MG. Revista Árvore 27:561-574.

MCCUNE, B. \& MEFFORD, M.J. 1999. PC-ORD Multivariate analysis of ecological data version 4.14 MjM Software. Gleneden Beach, Oregon.

MILARÉ, E. 1991. Legislação ambiental no Brasil. Edições APMP. Série: Cadernos informativos.

MMA - MINISTÉRIO DO MEIO AMBIENTE. 2003. Fragmentação de ecossistemas: causas, efeitos sobre a biodiversidade e recomendações de políticas públicas. MMA/SBF, Brasília.

MULLER-DOMBOIS, D. \& ELLENBERG, H. 1974. Aims and of vegetation ecology. Wiley \& Sons, New York.

MURCIA, C. 1995. Edge effects in fragmented forests: implications for conservation. Trends in Ecology and Evolution 10:58-62.

OLIVEIRA-FILHO, A.T., CURI, N., VILELA, E.A. \& CARVALHO, D.A. 2001. Variation in tree community composition and structure with changes in soil properties within a fragment of semideciduous forest in southeastern Brazil. Edinburgh Journal of Botany 58:139-158.

PEREIRA, I.M., OLIVEIRA-FILHO, A.T., BOTELHO, S.A., CARVALHO, W.A.C., FONTES, M.A.L., SCHIAVINI, I. \& SILVA, A.F. 2006. Composição florística do compartimento arbóreo de cinco remanescentes florestais do maciço do Itatiaia, Minas Gerais e Rio de Janeiro. Rodriguésia 57:103-126.

R DEVELOPMENT CORE TEAM. 2005. R: A language and environment for statistical computing. R Foundation for Statistical Computing. http://www.R-project.org (acesso em outubro de 2006).

RIZZINI, C.T. 1997. Tratado de fitogeografia do Brasil: aspectos ecológicos, sociológicos e florísticos. Âmbito Cultural Edições Ltda, Rio de Janeiro.

ROCHA, C.T.V., CARVALHO, D.A., FONTES, M.A.S., OLIVEIRA-FILHO, A.T., VAN DEN BERG, E. \& MARQUES, J.J.G.S.M. 2005. Comunidade arbórea de um continuum entre floresta paludosa e de encosta em Coqueiral, Minas Gerais, Brasil. Revista Brasileira de Botânica 28:203-217.

RODRIGUES, R.R. \& NAVE, A.G. 2000. Heterogeneidade florística das matas ciliares. In Matas ciliares: conservação e recuperação (R.R. Rodrigues \& H.F. Leitão Filho, eds.). Edusp, São Paulo, p.45-71.
RODRIGUES, R.R. \& SHEPHERD, G.J. 2000. Fatores condicionantes da vegetação ciliar. In Matas ciliares: conservação e recuperação (R.R. Rodrigues \& H.F. Leitão Filho, eds.). Edusp, São Paulo, p.101-107.

SALO, J. \& RÄSÄNEM, M. 1990. Hierarchy of landscape patterns in western Amazon. In Tropical forests: botanical dynamics, speciation and diversity (L.F. Holm-Nielsen, I.C. Nielsen \& H. Balslev, eds.). Academic Press, London, p.35-45.

SCHAAF, L.B., FIGUEIREDO-FILHO, A., GALVÃO, F. \& SANQUETTA, C.R. 2006. Alteração na estrutura diamétrica de uma floresta ombrófila mista no período entre 1979 e 2000. Revista Árvore 30:283-295.

SCHIAVINI, I. 1992. Estrutura das comunidades arbóreas de mata de galeria da Estação Ecológica do Panga (Uberlândia, MG). Tese de doutorado, Universidade Estadual de Campinas, Campinas.

SOUZA, V.C. \& LORENZI, H. 2005. Botânica sistemática: guia ilustrado pra identificação das famílias de Angiospermas da flora brasileira, baseado em APG II. Nova Odessa, São Paulo.

STATSOFT, INC. 2001. STATISTICA (Data analysis software system), version 6. http://www.statsoft.com (acesso em outubro de 2006).

TER BRAAK, C.J.F. 1987. The analysis of vegetation environment relationship by canonical correspondence analysis. Vegetatio 69:69-77.

TER BRAAK, C.J.F. 1995. Ordination. In Data analysis in community and landscape ecology (R.H.G. Jongman, C.J.F. ter Braak \& O.F.R. van Tongeren, eds.). Cambridge University Press, Cambridge, p.91-173.

VAN DEN BERG, E. \& OLIVEIRA-FILHO, A.T. 2000. Composição florística e estrutura fitossociológica de uma floresta ripária em Itutinga, MG, e comparação com outras áreas. Revista Brasileira de Botânica 23:231-253.

VAN DEN BERG, E., SANTOS, M., CARVALHO, G.C. \& FERREIRA, C.A. 2006. Estrutura do componente arbóreo de uma floresta de galeria aluvial em Poços de Caldas, MG. In Anais do $57^{\circ}$ Congresso Nacional de Botânica. $57^{\circ}$ Congresso Nacional de Botânica, Gramado, p.1-3.

VILELA, E.A., OLIVEIRA-FILHO, A.T., CARVALHO, D.A., GUILHERME, F.A.G. \& APPOLINÁRIO, V. 2000. Caracterização estrutural de floresta ripária do Alto Rio Grande, em Madre de Deus de Minas, MG. Cerne 6:41-54. 